\title{
Climate policies as a hedge against the uncertainty on future oil supply
}

\section{A letter}

\author{
Julie Rozenberg • Stéphane Hallegatte • \\ Adrien Vogt-Schilb • Olivier Sassi • Céline Guivarch • \\ Henri Waisman · Jean-Charles Hourcade
}

Received: 30 January 2010 / Accepted: 29 April 2010 / Published online: 25 June 2010

(C) The Author(s) 2010. This article is published with open access at Springerlink.com

Despite the inextricable link between oil scarcity and climate change (Toman 2002; Brown and Huntington 2008; Huntington and Brown 2004; Turton and Barreto 2006), the interplay between these two issues is paradoxically lacking a quantified analysis within a macroeconomic framework. This Climatic Change Letter uses a global energy-economy model to address this gap by assessing in a common framework both the costs of climate policies and oil scarcity, taking into account macroeconomic feedbacks. It shows that both costs are of the same order of magnitude. Moreover, our results suggest that, in the context of a limited and uncertain amount of ultimately recoverable oil resources, climate policies reduce the world vulnerability to peak oil. Of course, specific policies could also reduce this vulnerability. But by shifting energy use toward coal, they would lead to soaring greenhouse gases emissions. Climate policies, instead, can yield benefits from both sides: avoiding dangerous climate change (Mastrandrea and Schneider 2004) and hedging against the uncertainty on oil resources.

The amount of recoverable oil is extremely uncertain, and yet the world economy highly depends on it. Nevertheless, it is barely the only uncertain factor that may have a significant impact on all economies in the future. Major sources of uncertainty include, inter alia, future investments to sustain oil production; the strategy of MiddleEast oil producers that have a significant market power in the oil market; future coal prices; the ability of synfuels (biofuels and coal-to-liquid) to penetrate energy

Electronic supplementary material The online version of this article (doi: 10.1007/s10584-010-9868-8) contains supplementary material, which is available to authorized users.

J. Rozenberg (凶) · S. Hallegatte · A. Vogt-Schilb · O. Sassi · C. Guivarch · H. Waisman · J.-C. Hourcade

CIRED, 45bis avenue de la belle Gabrielle, 94736 Nogent-sur-Marne, France e-mail: rozenberg@centre-cired.fr

S. Hallegatte

Ecole Nationale de la Météorologie, Météo-France,

42 Av. G. Coriolis, 31057 Toulouse, France 
markets; the existence and penetration of carbon-free power generation technologies and of low-carbon end-use technologies in the transportation and residential sectors (Pacala and Socolow 2004); and future development patterns in the developing world. From a methodological point-of-view, this assessment has two consequences: first, the climate-energy issue should not be investigated assuming a Hotellinglike framework in which the final amount of recoverable oil is known and oil prices are perfectly anticipated by all actors (see for instance Pindyck 1978; Devarajan and Fisher 1982). A modeled world in which all actors know how and when oil production will decrease and energy prices will increase is qualitatively different from the real world, in which all actors have to make decisions in a context of high uncertainty on these important world-economy drivers. It may thus be useful to introduce the effect of imperfect anticipations in the analysis, in order to take this difference into account. The second consequence is that it appears as inadequate to assess climate policies in a modeled world assuming that only one baseline scenario is possible. Today, any investment has to be assessed taking into account many uncertainties, including the one on future energy prices. Investing in climate policies is no different.

Designing climate policies requires decision-making methods that go beyond deterministic cost-benefit analysis and account for uncertainty and progressive arrival of new information, like sequential decision-making (Ha-Duong et al. 1997) or robust decision-making (Lempert 2000). Informing such decision process demands quantifying the level of uncertainty associated to long-term scenarios. This paper presents an approach to address this requirement, through a sensitivity analysis of our energy-economy model, IMACLIM-R.

IMACLIM-R is a hybrid simulation model of the world economy (Hourcade 1993). A more developed description is available online in the Electronic Supplementary Material, and the model is fully detailed in Sassi et al. (2010). IMACLIM-R represents in a consistent framework the macro-economic and technological world evolutions. The growth engine is composed of exogenous demographic trends and of technical progress that increases labor productivity, as in Solow's neoclassical model of economic growth (Solow 1956). Demography simply follows UN median scenario and labor productivity is represented as an exogenous trend based on the convergence assumption, as it is common practice in the energy-environment modeling community. The two sets of assumptions on demography and labor productivity only prescribe potential growth. Actual economic growth then results endogenously from the interaction of these driving forces with short-term constraints: (1) available capital flows for investments ${ }^{1}$ and (2) under-utilization of production factors (labor and capital) due to the inadequacy between flexible relative prices (including wages) and inert capital vintages characteristics. Importantly, the model is not based on perfect expectations, but on adaptive expectations reacting on current price signals and past trends. IMACLIM-R, therefore, represents a "second-best" economy, i.e. a suboptimal economy in which resources can be under-utilized.

IMACLIM-R produces long-term scenarios of the world economy evolution and allows to explore the uncertainty that depends on unknown exogenous trends (e.g., future population) and parameter values that are debated or encompass poorly

\footnotetext{
${ }^{1}$ The amount of investment in each sector drives the pace of productive capacity expansion and the pace of embodied technical change.
} 
understood mechanisms. To get a better understanding of this uncertainty, we carried out a sensitivity analysis on selected exogenous parameters.

One difficulty arises from the multiplicity of parameters; we identified hundreds of parameters on which a sensitivity analysis can be useful, and each parameter can take an infinite number of values. To avoid combinatory explosion, the parameter domain has been simplified. First, the selected parameters are aggregated into a few consistent parameter sets. For instance, all parameters describing the future availability of oil and gas are aggregated into an "oil and gas markets" parameter set. Then, two or three sets of values are associated to each parameter set. For instance, the "oil and gas market" parameter set has three sets of possible values corresponding to increasing scarcity for both oil and gas; these sets of values are hereafter labeled as "Assumptions."

In this analysis, we selected eight sets covering the major drivers of macroenergetic contexts with assumptions on natural resources, technologies and international economic trends. These sets have been built based on expert opinion ${ }^{2}$ in such a way that the eight sets are as independent as possible. In this analysis, we assume also that the different possible values of each set are of equal probability. All sets are described in details in the Electronic Supplementary Material; the two most important for this study are:

Oil and gas markets: this set describes (1) the amount of ultimately recoverable resources; (2) the amount of Middle-East investment to sustain oil production at the oil field scale and to explore for new fields; (3) the inertia in non conventional production development; and (4) the indexation of gas prices on oil prices. In "Assumption 1" scenarios, these parameters are combined so that resources are abundant and easily extracted: oil production can reach $115 \mathrm{Mb}$ per day. In "Assumption 3" scenarios, oil and gas supplies are very constrained: production peaks below $95 \mathrm{Mb}$ per day. "Assumption 2" represents an intermediate situation with a production plateau around $95 \mathrm{Mb}$ per day.

Implementation of climate policies: the model simulates (1) a "Business As Usual" (BAU) world with no constraint on emissions, or (2) a "stabilization" world in which a carbon price reduces emissions such that $\mathrm{CO}_{2}$ concentration is stabilized at $450 \mathrm{ppm}$ in the long run. In stabilization scenarios, revenues from carbon tax or auctioned emissions allowances are either entirely given back to households, or recycled following a lump-sum principle in which each sector receives back what it paid.

We carried out an exhaustive exploration of all the combinations for the eight sets, leading to 576 scenarios. Of course, our parameter set does not cover all the uncertainty in scenarios. For instance, no population or productivity growth parameter has been included in the sensitivity analysis, for we want to focus on the uncertainty arising from the energy system and climate policies.

In our exercises, we measure the costs of oil scarcity and of climate policies using the same metric, namely the sum of the Gross World Product (GWP) over the 20102050 period, discounted at a 3\% discount rate. The costs are measured as the relative difference (in percent) between the discounted summed GWP in two scenarios (e.g.,

\footnotetext{
${ }^{2}$ Expert opinion includes inter alia data from bottom-up models such as POLES (LEPII-EPE 2006), and data from the IEA (Fulton and Eads 2004; IEA 2008) and private business experts on technological potentials. See Electronic Supplementary Material for more information.
} 
with vs. without climate policies, everything else being equal; with more or less oil scarcity, everything else being equal).

We find that, in our model, the cost of oil scarcity is significant (see Table 1). In the BAU scenarios, for instance, oil scarcity has a large impact on GWP, and the 3\%-discounted GWP over the 2010-2050 period is reduced on average by $2.6 \%$ in Assumption 3 scenarios (oil is scarce) compared with Assumption 1 scenarios (oil is largely available). Depending on assumptions on the other parameter sets (see Electronic Supplementary Material), these BAU losses range from $1.8 \%$ to $3.7 \%$. They are due to changes in oil price trajectories, which affect production costs and purchasing power. The additional rent transfer from oil-importers to oilexporters due to higher oil prices is indeed not only a transfer of resources. This higher rent has a negative impact on economic activity at the global scale because of various macroeconomic effects (exchange rates appreciation, changes in investment decisions, modification of capital and goods international flows, and technologies) and thus reduces GWP. The impact of climate policies is significant as well, since they cost $1.2 \%$ GWP on average.

Most importantly, oil scarcity and climate policy interact with each other. Our results demonstrate that GWP losses from the combination of climate policies and strong oil scarcity are smaller than the sum of both effects taken separately (see Table 1). The cost of climate policies is indeed strongly correlated with oil resources: with large resources (Assumption 1) this cost is much higher (1.7\% on average) than when oil resources are scarce $(0.7 \%$ on average in Assumption 3$)$. It is important to note that this lower cost when oil is scarce does not arise from lower baseline emissions. Even in the scenario of highest oil scarcity, baseline emissions in 2050 are well above the $450 \mathrm{ppm}$ target, in particular because coal consumption replaces oil through coal-to-liquid. Consequently, the reduction in emissions between the baseline and the stabilized scenario is about the same in the three options of the oil and gas parameter set, and tighter oil scarcity does not necessarily help meet the $\mathrm{CO}_{2}$ concentration target.

In fact, climate policies are less costly when oil is scarce because, in addition to their benefits in terms of avoided climate impacts, they bring important cobenefits in terms of resilience to oil scarcity. These co-benefits are illustrated by Fig. 1, which represents the histograms of GWP losses due to oil scarcity, with a distinction between scenarios without climate policies (BAU) and with climate policies (450 ppm). Two important results emerge: first, the $450 \mathrm{ppm}$ histogram is shifted to the left, indicating that the mean loss due to oil scarcity is reduced by climate policies; second, the large right tail of the BAU distribution disappears in

Table 1 Changes in the 3\%-discounted GWP over the 2010-2050 period (mean [min ; max]) caused by fossil fuels constraints and climate policies

\begin{tabular}{llll}
\hline & $\begin{array}{l}\text { Assumption 1: } \\
\text { oil and gas largely } \\
\text { available }\end{array}$ & $\begin{array}{l}\text { Assumption 2: } \\
\text { oil and gas limited }\end{array}$ & $\begin{array}{l}\text { Assumption 3: } \\
\text { oil and gas very } \\
\text { constrained }\end{array}$ \\
\hline BAU & Reference case & $-\mathbf{1 . 3} \%[-0.6 ;-2.1]$ & $-\mathbf{2 . 6} \%[-1.8 ;-3.7]$ \\
$450 \mathrm{ppm}$ & $\mathbf{- 1 . 7} \%[-0.4 ;-4.4]$ & $\mathbf{- 2 . 3} \%[-1.0 ;-4.8]$ & $-\mathbf{3 . 3} \%[-2.0 ;-5.7]$ \\
Net cost of climate policies & $1.7 \%[0.4 ; 4.4]$ & $1.0 \%[0.0 ; 3.1]$ & $0.7 \%[0.0 ; 2.7]$ \\
\hline
\end{tabular}

The reference case has abundant oil ressources and no climate policies. Losses from the combination of climate policies and strong oil scarcity are smaller than the sum of both effects taken separately 


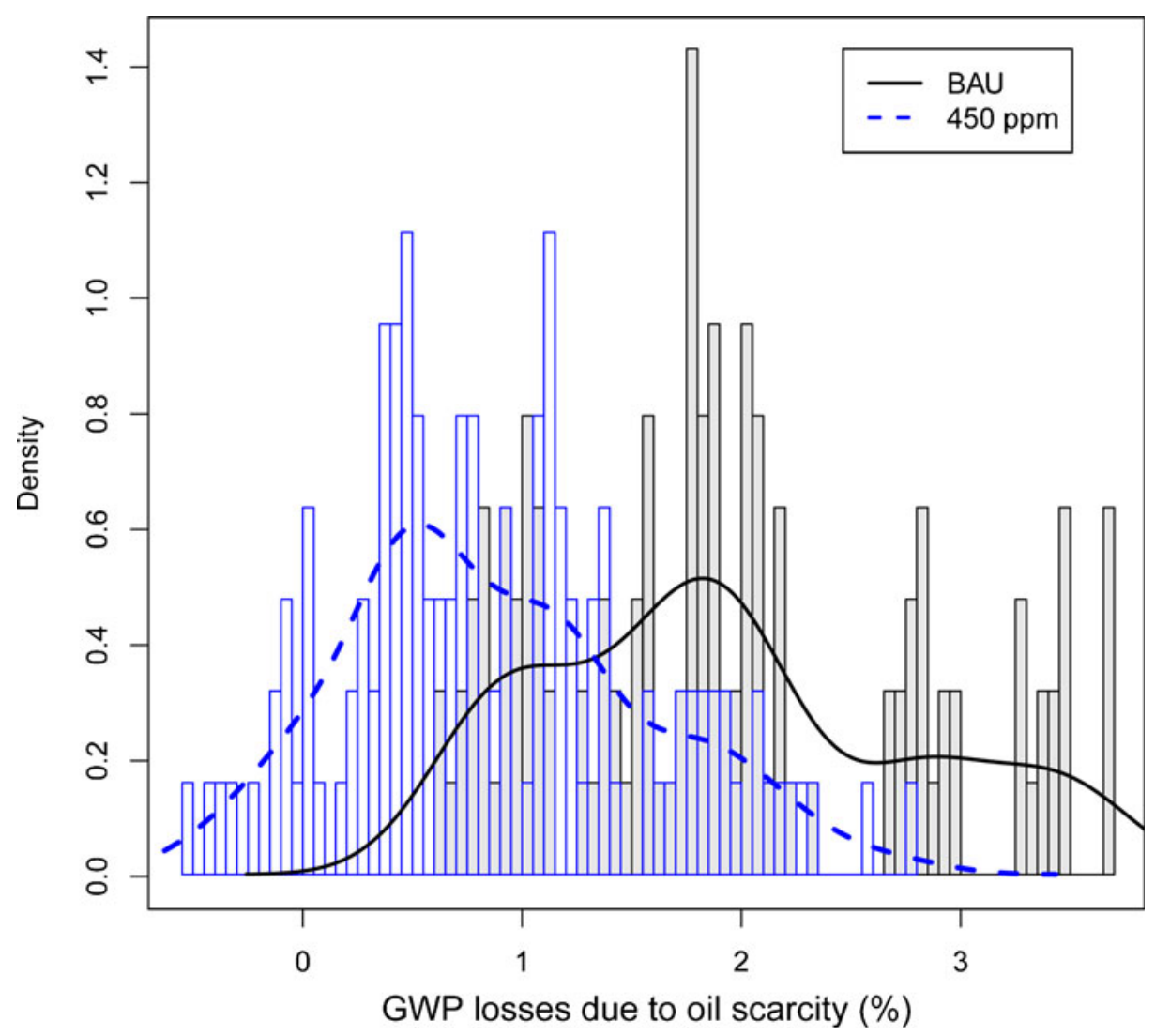

Fig. 1 Histogram and smoothed densities of GWP losses (in \%) due to constrained oil supply (discounted GWP between 2010 and 2050, with a 3\% discount rate). Black filled bars and plain line for BAU scenarios; blue empty bars and dashed line for $450 \mathrm{ppm}$-stabilization scenarios. The $450 \mathrm{ppm}$ histogram is shifted to the left compared with the BAU one, indicating that losses from oil scarcity are larger in absence of climate policies

the $450 \mathrm{ppm}$ distribution, meaning that climate policies eliminate a large number of scenarios with high GWP losses (larger than 3\% and reaching up to $3.7 \%$ ). These large mitigation co-benefits can be explained by earlier and more regular increases in final oil price. In a second-best world where anticipations are imperfect, indeed, brutal increases in energy prices cause larger welfare losses than slower increases (Nordhaus 2007). Here, the more regular increase in energy price with climate policies prevents economic lock-ins in oil-dependent schemes and promotes the development (induced technical change) and diffusion (investment incentive) of oil-free technologies before the beginning of the depletion phase in oil production.

Climate policies, therefore, can be considered as a hedge against the potential negative impact of oil scarcity on the world economy. This hedge parallels the climate-related hedge of early climate policies (see Yohe et al. 2004; Manne and Richels 1992). Its net present value can be calculated as the difference between economic losses due to oil scarcity without climate policies and the same losses with climate policies; see Electronic Supplementary Material. A simple calculation 
suggests that this hedge has a net present value of about US $\$ 11,500$ billion, that is $19 \%$ of the 2009 Gross World Product. The overall welfare cost of climate policies is thus significantly reduced, which is a powerful incentive to adopt more stringent climate targets. Eventually, reducing the risk of future economic losses due to oil scarcity may appear as a significant side-benefit of climate policies to many decision-makers.

Acknowledgements The authors wish to thank Mike Mastrandrea for his useful comments on a previous version of this article. All remaining errors are the authors'. We are also grateful to two anonymous reviewers who helped us improve our article.

This research was supported by the European Commission's project FP7-SSH-2009-A "AUGUR" and the Chair "Modeling for sustainable development", led by Mines ParisTech, Ecole des Ponts ParisTech, AgroParisTech and ParisTech. The views expressed in this article are the authors' and do not necessarily reflect the views of the aforementioned institutions.

Open Access This article is distributed under the terms of the Creative Commons Attribution Noncommercial License which permits any noncommercial use, distribution, and reproduction in any medium, provided the original author(s) and source are credited.

\section{References}

Brown SP, Huntington HG (2008) Energy security and climate change protection: complementarity or tradeoff? Energy Policy 36(9):3510-3513. doi:10.1016/j.enpol.2008.05.027

Devarajan S, Fisher AC (1982) Exploration and scarcity. J Polit Econ 90(6):1279-1290

Fulton L, Eads G (2004) IEA/SMP model documentation and reference case projection. Tech. rep.

Ha-Duong M, Grubb M, Hourcade JC (1997) The influence of inertia and uncertainty upon optimal $\mathrm{CO}_{2}$ policies. Nature 390:270-274

Hourcade JC (1993) Modelling long-run scenarios: methodology lessons from a prospective study on a low $\mathrm{CO}_{2}$ intensive country. Energy Policy 21(3):309-326

Huntington HG, Brown SPA (2004) Energy security and global climate change mitigation. Energy Policy 32(6):715-718. doi:10.1016/S0301-4215(03)00105-8

IEA (2008) World energy outlook. Tech. rep., IEA/OECD, Paris, France

Lempert R (2000) Robust strategies for abating climate change. Clim Change 45:387-401

LEPII-EPE (2006) The POLES model, POLES state of the art. Institut d'économie et de Politique de l'énergie, Grenoble, France. http://upmfgrenoble.fr/iepe/Recherche/Rech5.html

Manne AS, Richels RG (1992) Buying greenhouse insurance: the economic costs of carbon dioxide emission limits. MIT Press, Cambridge, MA

Mastrandrea MD, Schneider SH (2004) Probabilistic integrated assessment of "dangerous" climate change. Science 304(5670):571-575. doi:10.1126/science.1094147

Nordhaus WD (2007) Who's afraid of a big bad oil shock? Prepared for the Brookings Panel on Economic Activity

Pacala S, Socolow R (2004) Stabilization wedges: solving the climate problem for the next 50 years with current technologies. Science 305(5686):968-972. doi:10.1126/science.1100103

Pindyck RS (1978) The optimal exploration and production of nonrenewable resources. J Polit Econ 86(5):841-861

Sassi O, Hourcade J, Crassous R, Gitz V, Waisman H, Guivarch C (2010) IMACLIM-R: a modeling framework for sustainable development issues. International Journal of Global Environmental Issues 10(1-2):5-24

Solow RM (1956) A contribution to the theory of economic growth. Q J Econ 70:65-94

Toman MA (2002) International oil security: problems and policies. The Brookings Review, pp 20-23

Turton H, Barreto L (2006) Long-term security of energy supply and climate change. Energy Policy 34(15):2232-2250. doi:10.1016/j.enpol.2005.03.016

Yohe G, Andronova N, Schlesinger M (2004) Climate: to hedge or not against an uncertain climate future? Science 306(5695):416-417. doi:10.1126/science.1101170 